structures, 41 knee structures, 14 ankle structures and 2 foot structures. The number of structures described for each joint part was as follows: 3 shoulder, 13 elbow, 2 wrist, 4 hand, 7 hip, 25 knee, 14 ankle, 1 foot.

Conclusions: Several anatomical structures are lacking standardized MSUS examination in children.

Disclosure of Interest: None declared

DOI: 10.1136/annrheumdis-2017-eular.5202

\section{FRI0650 NON OMERACT -EXPERT RHEUMATOLOGISTS SONOGRAPHERS AND INTER-ULTRASOUND MACHINE RELIABILITY OF THE OMERACT ULTRASOUND SCORING IN RHEUMATOID ARTHRITIS IN A CLINICAL-BASED SETTING: A BELGIAN STUDY}

J.-P. Hauzeur $^{1}$, M.-J. Kaiser ${ }^{2}$, J. Bentin ${ }^{3}$, J.-P. Brasseur ${ }^{4}$, B. André ${ }^{2}$, P. Carron ${ }^{5}$, E. Deflandre ${ }^{2}$, C. Naveau ${ }^{6}$, C. Ribbens ${ }^{2}$, C. Rinkin ${ }^{2}$, R. Wittoek ${ }^{5}$,

M.-A. D'Agostino ${ }^{7}$, V. De Maertelaer ${ }^{8}$ on behalf of The Belgian Group of

Ultrasonography in Rheumatology. ${ }^{1}$ Rheumatology, CHIREC, Braine l'Alleud;

${ }^{2}$ Rheumatology, CHU Liège, Liege: ${ }^{3}$ Rheumatology, CHU Brugmann, Brussels;

${ }^{4}$ Rheumatology, CHU Mont-Godinne, Yvoir; ${ }^{5}$ Rheumatology, Ghent University Hospital, Ghent; ${ }^{6}$ Rheumatology, GHDC, Charleroi, Belgium; ${ }^{7}$ Rheumatology, hôpital Ambroise Paré, Boulogne-Billancourt, France; ${ }^{8}$ Biostatistics and Medical Informatics \& IRIBHM, School of Medicine, ULB, Brussels, Belgium

Background: The OMERACT Ultrasound scoring system (USSS) of joint in RA has been shown to be reliable and sensitive to change when used in clinical trial setting. However it is unclear whether this reliability is also achieved in clinical daily practice among Rheumatologists performing US in a non-research setting and using different machines.

Objectives: To assess agreement between non-research sonographers in scoring synovitis using the OMERACT USSS and using the scoring of an OMERACT expert as gold standard. To assess the reliability of the USSS by using different US machines.

Methods: First an OMERACT US expert presented the scoring method and supervised a training session. The wrist, MCP 2 and 3 joints of the left hand (dorsal aspect) of 3 RA patients were then successively evaluated by 9 Rheumatologists with 3 different US machines: Hitachi Arietta $=$ H, GE Logic E9 $=\mathrm{G}$. Esaote MyLab 7=E. The USSS included B-mode acquisition of synovial hypertrophy (SH), joint effusion (JE) and bone erosion (BE), and Power-Doppler $(\mathrm{PD})$ activity. JE, $\mathrm{SH}$ and $\mathrm{BE}$ were scored binary; $\mathrm{SH}$ and $\mathrm{PD}$ were score semi quantitatively ( 0 to 3 ), by both the 9 participating Rheumatologists and the OMERACT US expert. The agreement between each participant with the scoring of the OMERACT US expert was quantified by proportions. The inter-US machine reproducibility was assessed by kappa statistics for discrete variables and weighted kappa's for ordinate.

Results: The 3 joints of 3 patients each were evaluated on the 4 US items (SH, JF, BE, PD) on a different US machine. So 27 values were obtained for each joint within each item. The percentages of exact agreement (PEA) between these 27 values and the scores of the OMERACT US expert were calculated and ranged between $33 \%$ (9/27) for SH-MCP3, 37\% for JF-MCP2 and PD-Wrist, $41 \%$ for SH-wrist, 48\% BE-MCP3, 52\% PD-MCP3, 56\% PD-MCP3, 59 JF-wrist and BE-MCP2, 63\% JF-MCP3, 67\% SH-MCP2 and 78\% (21/27) for BE-wrist. For the inter-US machines reproducibility, kappa between the 3 machines was calculated on 9 data (3 patients $\times 3$ joints). The reliability was low for detecting JE $\leq 0.211$. Acceptable reliability among machines was found for SH, BE and PD (table 1).

Table 1

\begin{tabular}{lcccc}
\hline & & $\mathrm{H} / \mathrm{G}$ & $\mathrm{H} / \mathrm{E}$ & $\mathrm{E} / \mathrm{G}$ \\
\hline Kappa values & $\mathrm{JF}$ & 0,211 & 0,143 & 0,211 \\
& SH & 0,529 & 0,602 & 0,584 \\
& $\mathrm{PD}$ & 0,455 & 0,709 & 0,434 \\
Corresponding P-values & $\mathrm{BE}$ & 0,628 & 0,615 & 0,550 \\
& JF & 0,357 & 0,588 & 0,357 \\
& SH & $<0,001$ & $<0,001$ & $<0,001$ \\
& PD & 0,001 & $<0,001$ & $<0,001$ \\
& $\mathrm{BE}$ & 0,002 & 0,003 & 0,004 \\
\hline
\end{tabular}

Conclusions: Non OMERACT-expert Rheumatologists can apply the USSS, and this score works well across different machines. The difference among machines and sonographers is mostly captured by the low reliability of JE. The OMERACT USSS could be used by sonographers in their everyday clinical practice to evaluate the activity of RA patients. Further studies in clinical-based settings will allow to define more precisely the applicability of this scoring system.

Disclosure of Interest: None declared

DOI: 10.1136/annrheumdis-2017-eular.5435

\section{FRI0651 OBSERVATIONAL REPRODUCIBILITY STUDY OF UCO-TRACK ${ }^{\odot}$, AN AUTOMATIZED MEASUREMENT OF MOBILITY, IN PATIENTS WITH AXIAL SPONDYLOARTHRITIS}

J. Garrido $^{1}$, E. Collantes ${ }^{2}$, J. Mulero ${ }^{3}$, B. Flores ${ }^{3}$, P. Zarco ${ }^{4}$, R. Mazzucchelli ${ }^{4}$, M. Domínguez-González ${ }^{4}$, L. Carmona ${ }^{5}$, L. Cea-Calvo ${ }^{6}$, M. Arteaga ${ }^{6}$,

R. Curbelo ${ }^{5} .{ }^{1}$ I. Mamónides; ${ }^{2} \mathrm{H}$ Reina Sofía, Córdoba; ${ }^{3} \mathrm{H}$ Puerta de Hierro; ${ }^{4} \mathrm{H}$ Fundación Alcorcón; ${ }^{5}$ I. Salud Muscular; ${ }^{6}$ Medical Affairs, Merck Sharp \& Dohme, Madrid, Spain

Background: The classical measures of spinal mobility for the assessment of patients with axial spondyloarthritis $(\mathrm{SpA})$, such as BASMI, are subject to inter-observer variability.

Objectives: We assessed the reproducibility of the UCOASMI index (University of Córdoba Ankylosing Spondylitis Metrology Index), a composite index of cervical and spinal mobility obtained with the UCOTrack ${ }^{\odot}$ motion analysis system (an innovative 3D motion capture system based on video-images) [1], in patients with axial SpA.

Methods: An observational study of repeated measures was carried out in 3 Spanish centers with the technology available $(\mathrm{H}$. Reina Sofía, Córdoba, H. Puerta de Hierro, Madrid and H. Fundación Alcorcón, Madrid). For the assessment of intra-observer reliability, 30 patients (10 per center) were evaluated twice, 3-5 days apart. For the inter-observer reliability, 9 patients were evaluated in the 3 centers by 3 observers (window 3-7 days). The Intraclass Correlation Coefficients (ICC) for UCOASMI and classical metrology measurements were calculated.

Results: We included 30 patients ( $73 \%$ men, mean age 52 [SD 9], mean BASDAI 3.3 [SD 2]). The table shows the intra- and inter-observer reliability values. The reproducibility of UCOASMI was very high, with inter-observer ICC 0.99 , and intraobserver ICC $0.97,0.97$ and 0.99 , higher than most conventional measurements. The Schober test and cervical rotation showed lower reproducibility (inter-observer ICC between 0.58 and 0.68 ) and variable intra-observer ICC.

Conclusions: The reproducibility of the UCOASMI, obtained through the UCOTrack $^{\odot}$ motion analysis system in the 3 centers, was very high, in contrast to the lower reproducibility of the Schobert test and other measures of classical metrology. The reliability of this system opens the door to using this technology to monitor SpA patients and in future research studies.

\section{References:}

[1] Garrido-Castro JL, Escudero A, Medina-Carnicer R, et al. Validation of a new objective index to measure spinal mobility: the University of Cordoba Ankylosing Spondylitis Metrology Index (UCOASMI). Rheumatol Int 2014;34:401-6.

Acknowledgements: Funded by MSD, Spain

Disclosure of Interest: None declared

DOI: 10.1136/annrheumdis-2017-eular.3654

\section{FRI0652 MEDIAN NERVE ULTRASOUND FINDINGS AND CLINICAL CORRELATIONS IN PATIENTS WITH SYSTEMIC SCLEROSIS: A COMPARATIVE ANALYSIS WITH MATCHED CONTROL SUBJECTS}

J. Sousa-Neves ${ }^{1}$, M. Cerqueira ${ }^{1}$, D. Santos-Faria ${ }^{1}$, J. Leite Silva ${ }^{1}$, A. Raposo ${ }^{2}$ C. Afonso ${ }^{1}$, F. Teixeira ${ }^{1} .{ }^{1}$ Rheumatology, Hospital Conde de Bertiandos, ULSAM, Ponte de Lima: ${ }^{2}$ Rheumatology, Centro Hospitalar Trás-os-Montes e Alto Douro, Vila Real, Portugal

Background: Median nerve (MN) entrapment in the carpal tunnel seems to be common in patients with Systemic Sclerosis (SSc). Ultrasound (US) evaluation of $\mathrm{MN}$ in SSc patients was performed in some previous studies but conclusions were not linear (1).

Objectives: To compare specific MN US parameters of patients with SSc and a group of age and sex matched controls. To understand if specific clinical variables correlate with US parameters assessed in the group of SSc patients.

Abstract FRI0651 - Table

\begin{tabular}{|c|c|c|c|c|}
\hline & \multirow{2}{*}{$\begin{array}{l}\text { Inter-observer reliability } \\
\qquad \text { ICC }(95 \% \mathrm{CI})\end{array}$} & \multicolumn{3}{|c|}{ Intra-observer reliability } \\
\hline & & $\begin{array}{c}\text { Observer } 1 \\
\text { ICC }(95 \% \mathrm{Cl})\end{array}$ & $\begin{array}{c}\text { Observer } 2 \\
\text { ICC }(95 \% \mathrm{CI})\end{array}$ & $\begin{array}{c}\text { Observer } 3 \\
\text { ICC }(95 \% \mathrm{CI})\end{array}$ \\
\hline UCOASMI & $0.99(0.98-1.00)$ & $0.99(0.98-1.00)$ & $0.97(0.94-1.00)$ & $0.97(0.93-1.00)$ \\
\hline \multicolumn{5}{|l|}{ Conventional Metrology } \\
\hline BASMI & $0.50(0.11-0.89)$ & $0.78(0.54-1.00)$ & $0.61(0.21-1.00)$ & $0.99(0.97-1.00)$ \\
\hline Right lateral flexion & $0.83(0.64-1.00)$ & $0.94(0.87-1.00)$ & $0.91(0.80-1.00)$ & $0.96(0.91-1.00)$ \\
\hline Left lateral flexion & $0.88(0.75-1.00)$ & $0.96(0.92-1.00)$ & $0.93(0.85-1.00)$ & $0.97(0.94-1.00)$ \\
\hline Right tragus-wall distance & $0.97(0.95-1.00)$ & $0.96(0.91-1.00)$ & $0.91(0.81-1.00)$ & $0.99(0.98-1.00)$ \\
\hline Left tragus-wall distance & $0.97(0.95-1.00)$ & $0.96(0.91-1.00)$ & $0.90(0.78-1.00)$ & $0.98(0.97-1.00)$ \\
\hline Schöber test & $0.68(0.39-0.97)$ & $0.64(0.27-1.00)$ & $0.98(0.97-1.00)$ & $0.95(0.89-1.00)$ \\
\hline Intermaleolar distance & $0.87(0.73-1.00)$ & $0.93(0.85-1.00)$ & $0.82(0.61-1.00)$ & $0.98(0.97-1.00)$ \\
\hline Right cervical rotation & $0.65(0.33-0.96)$ & $0.82(0.61-1.00)$ & $0.94(0.87-1.00)$ & $0.98(0.97-1.00)$ \\
\hline Left cervical rotation & $0.58(0.22-0.94)$ & $0.91(0.81-1.00)$ & $0.75(0.47-1.00)$ & $0.98(0.97-1.00)$ \\
\hline
\end{tabular}

